\title{
Comunicação
}

[Communication]

\section{Hemograma e proteínas do soro sanguíneo de bezerros Canchim-Nelore e da raça Holandesa nos primeiros 30 dias de vida}

\author{
[Hemogram and serum proteins of Canchim-Nelore and Holstein calves in the first 30 days of life] \\ T.G. Rocha ${ }^{1}$, C. Franciosi ${ }^{1}$, R.P. Nociti ${ }^{2}$, C.A.S. Nogueira ${ }^{3}$, J.J. Fagliari ${ }^{3 *}$ \\ ${ }^{1}$ Aluna de pós-graduação - FCAV-UNESP - Jaboticabal, SP \\ ${ }^{2}$ Aluno de graduação - FCAV-UNESP - Jaboticabal, SP \\ ${ }^{3}$ Faculdade de Ciências Agrárias e Veterinárias - UNESP \\ Via de Acesso Prof. Paulo D. Castellane, s/n \\ 14884-900 - Jaboticabal, SP
}

\begin{abstract}
A realização de exames e a interpretação de dados laboratoriais dos ruminantes podem ser uma extensão importante do exame físico, pois auxiliam na determinação da etiologia, quando os achados clínicos são vagos, e fornecem informações que norteiam a abordagem terapêutica e o prognóstico (Jones e Allison, 2007; Mohri et al., 2007). No entanto, vários fatores podem influenciar os constituintes sanguíneos, e intervalos de referência específicos são necessários para raça, espécie e faixa etária (Mohri et al., 2007).
\end{abstract}

Em bovinos, as alterações que ocorrem nos valores hematológicos desde o nascimento até a idade adulta já são conhecidas (Costa et al., 2000; Mohri et al., 2007), no entanto poucos trabalhos encontrados na literatura (Jain, 1993; Fagliari et al., 1998) fornecem dados suficientes para avaliar os animais com diferentes aptidões. A avaliação do proteinograma também é de grande importância do ponto de vista diagnóstico, e albumina e globulinas são as frações mais importantes.

Sabe-se que as diferenças entre o manejo extensivo e intensivo, empregados de acordo com a aptidão dos animais, bem como o número de parições da vaca e a idade do bezerro, podem ocasionar diferenças relevantes no perfil hematológico desses animais. Dessa forma, o objetivo deste estudo foi comparar o perfil hematológico e proteico de bezerros Canchim-
Nelore e da raça Holandesa saudáveis, filhos de vacas primíparas ou pluríparas, do nascimento aos 30 dias de idade.

O protocolo experimental empregado foi avaliado e aprovado pela Comissão de Ética e Bem-estar Animal (CEBEA), sob números 009793-08 e 009795-08.

Foram analisadas amostras de sangue de 16 bezerros recém-nascidos sadios, oito deles oriundos do cruzamento das raças Canchim e Nelore, sendo quatro filhos de vacas primíparas (grupo 1) e quatro de vacas pluríparas (grupo 2), e oito da raça Holandesa, sendo quatro filhos de vacas primíparas (grupo 3) e quatro de vacas pluríparas (grupo 4). Durante a fase experimental, os bezerros Canchim-Nelore permaneceram junto às mães, em pastagem de Brachiaria brizantha CV Marandu, e os da raça Holandesa receberam colostro materno logo após o nascimento e, em seguida, foram mantidos em bezerreiros, onde recebiam leite in natura, em volume correspondente a $10 \%$ do peso corporal, fracionado em duas vezes ao dia.

Para realização do hemograma, amostras de sangue foram obtidas por venopunção jugular em quatro momentos: 12-24 horas após o nascimento e aos sete, 15 e 30 dias de idade, em tubos a vácuo contendo solução de ácido etilenodiaminotetracético (EDTA) 10\%. Para a determinação das concentrações séricas de

Recebido em 26 de abril de 2010

Aceito em 20 de setembro de 2010

* Autor para correspondência (corresponding author)

E-mail: fagliari@fcav.unesp.br 
proteína total e albumina, foram coletadas amostras de sangue em tubos a vácuo, sem anticoagulante, nos mesmos momentos mencionados para o hemograma.

As contagens de hemácias e de leucócitos e a determinação do teor de hemoglobina foram realizadas em contador semiautomático (CELMCC510) padronizado para a espécie em estudo. O volume globular foi obtido pela técnica do microematócrito e a contagem diferencial de leucócitos foi obtida em esfregaço sanguíneo, após coloração de Rosenfeld modificada (Thrall, 2007). Os valores de volume globular médio (VGM), concentração de hemoglobina globular média (CHGM) e hemoglobina globular média (HGM) foram calculados a partir de fórmulas matemáticas (Birgel, 1982).

As concentrações séricas de proteína total (método do biureto) e de albumina (método do verde de bromocresol) foram determinadas utilizando-se conjunto de reagentes comerciais (Labtest Diagnóstica - Belo Horizonte, Brasil); a leitura das amostras foi realizada em espectrofotômetro semi-automático (Labquest) com comprimento de onda adequado a cada constituinte. $\mathrm{O}$ teor de globulinas foi determinado pela diferença matemática entre o teor de proteína total e da fração albumina.

Os resultados da avaliação hematológica e das proteínas séricas foram submetidos à análise de variância e ao teste Tukey para contraste entre pares de médias, a 5\% de significância. Não se constatou diferença entre grupos na contagem de hemácias no sangue colhido às 12-24 horas após o nascimento, e a contagem de hemácias dos bezerros da raça Holandesa, filhos de vacas pluríparas, foi significativamente mais baixa que a dos demais grupos aos sete, 15 e 30 dias de idade (Tab. 1). Muito embora tenha sido verificada redução na contagem de eritrócitos no decorrer do primeiro mês de vida nos animais do grupo 4, os valores em todos os grupos mantiveram-se nos limites de normalidade para a espécie, fato também notado por Fagliari et al. (1998).

Nos bezerros do grupo 1, verificou-se que o teor de hemoglobina decresceu do nascimento aos 30 dias de idade; nos do grupo 3, as médias foram significativamente menores do que as dos demais grupos no decorrer do período experimental, sendo também menores nos animais do grupo 4 aos 15 e 30 dias de idade. O decréscimo no teor de hemoglobina a partir do nascimento verificado no grupo 1 já havia sido relatado por Fagliari et al. (1998) e Mohri et al. (2007). Segundo Getty et al. (1968), verifica-se ampla variação de teores de hemoglobina em bezerros com menos de 20 semanas de idade.

O volume globular foi menor nos bezerros do grupo 4 às 12-24 horas de vida e aos 15 e 30 dias de idade, quando comparado ao dos demais grupos (Tab. 1). Entre momentos, verificaram-se menores médias no grupo 1 , aos sete e 30 dias de idade, e no grupo 3 aos 30 dias de idade. Mohri et al. (2007) relataram redução do volume globular do nascimento até três semanas de vida, no entanto essa tendência só foi constatada nos bezerros mestiços Canchim-Nelore, filhos de vacas primíparas.

O VGM foi mais elevado nos bezerros do grupo 4 aos 30 dias de idade, quando comparado aos dos demais grupos no mesmo momento (Tab. 1). O VGM manteve-se no intervalo de referência para a espécie em todos os grupos, segundo Jones e Allison (2007), e foi mais alto nos do grupo 4, aos 30 dias de idade, quando comparado aos dos demais momentos.

Não se constatou diferença significativa na CHGM entre grupos ou entre momentos, e os valores variaram de $29,0 \pm 2,56$ a $34,0 \pm 0,72 \mathrm{~g} / \mathrm{dL}$. Todos os grupos apresentaram CHGM nos intervalos de referência para a espécie, com exceção do grupo 3, cujos valores foram ligeiramente mais baixos. Segundo Jain (1993), a idade influencia pouco a CHGM, no entanto Jones e Allison (2007) afirmaram que bezerros com menos de cinco semanas de idade podem apresentar CHGM relativamente baixa, em comparação à de adultos.

O valor da HGM foi mais baixo nos bezerros dos grupos 1 e 3 aos 30 dias de idade (Tab. 1). Os bezerros do grupo 4 apresentaram valores menores às 12-24 horas e aos sete e 15 dias de vida quando comparados aos valores verificados aos 30 dias. Relatos anteriores citaram que a HGM é mais alta ao nascimento, e diminui gradualmente para o nível aproximado dos animais adultos (Jain, 1993; Mohri et al. 2007), o inverso do verificado nos animais do grupo 4. 
Tabela 1. Médias e erros-padrão da média de parâmetros hematológicos de bezerros Canchim-Nelore, filhos de vacas primíparas (G1) e pluríparas (G2) e de bezerros da raça Holandesa, filhos de vacas primíparas (G3) e pluríparas (G4), às 12-24h após o nascimento, e aos sete, 15 e 30 dias de idade

\begin{tabular}{|c|c|c|c|c|}
\hline \multirow{2}{*}{ Grupo } & \multicolumn{4}{|c|}{ Momento } \\
\hline & 12-24 horas & 7 dias & 15 dias & 30 dias \\
\hline \multicolumn{5}{|c|}{ Hemácias $\left(\right.$ x $\left.10^{6} / \mu \mathrm{L}\right)$} \\
\hline G1 & $9,15 \pm 0,79$ Aa & $8,50 \pm 0,87 \mathrm{ABa}$ & $8,68 \pm 0,67 \mathrm{Aa}$ & $8,34 \pm 0,30 \mathrm{Aa}$ \\
\hline $\mathrm{G} 2$ & $8,73 \pm 0,26 \mathrm{Aa}$ & $8,94 \pm 0,55 \mathrm{Aa}$ & $8,88 \pm 0,42 \mathrm{Aa}$ & $9,16 \pm 0,62 \mathrm{Aa}$ \\
\hline G3 & $8,07 \pm 0,45 \mathrm{Aa}$ & $7,52 \pm 0,88 \mathrm{ABa}$ & $8,15 \pm 0,67 \mathrm{ABa}$ & 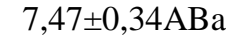 \\
\hline G4 & $7,27 \pm 0,63 \mathrm{Aa}$ & $6,27 \pm 0,71 \mathrm{Bab}$ & $5,87 \pm 0,94 \mathrm{Bb}$ & $5,00 \pm 0,95 \mathrm{Bb}$ \\
\hline \multicolumn{5}{|c|}{ Hemoglobina $(\mathrm{g} / \mathrm{dL})$} \\
\hline G 1 & $14,9 \pm 1,71 \mathrm{Aa}$ & $13,9 \pm 1,57 \mathrm{ABab}$ & $13,7 \pm 1,14 \mathrm{ABab}$ & $12,3 \pm 1,09 \mathrm{ABb}$ \\
\hline G 2 & $14,9 \pm 0,36 \mathrm{Aa}$ & $14,5 \pm 0,38 \mathrm{Aa}$ & $14,7 \pm 0,48 \mathrm{Aa}$ & $14,8 \pm 0,73 \mathrm{Aa}$ \\
\hline G 3 & $10,5 \pm 0,99 \mathrm{Ba}$ & $10,1 \pm 0,79 \mathrm{Ba}$ & $10,0 \pm 0,75 \mathrm{Ba}$ & $9,02 \pm 0,80 \mathrm{Ba}$ \\
\hline G 4 & $10,8 \pm 1,12 \mathrm{ABa}$ & $10,9 \pm 1,00 \mathrm{ABa}$ & $9,85 \pm 1,22 \mathrm{Ba}$ & $9,77 \pm 1,22 \mathrm{Ba}$ \\
\hline \multicolumn{5}{|c|}{ Volume globular (\%) } \\
\hline G 1 & $46,0 \pm 4,32 \mathrm{Aa}$ & $41,2 \pm 4,75 \mathrm{Ab}$ & $41,7 \pm 3,35 \mathrm{ABab}$ & $40,0 \pm 1,78 \mathrm{ABb}$ \\
\hline G 2 & $46,0 \pm 0,91 \mathrm{Aa}$ & $42,7 \pm 0,48 \mathrm{Aa}$ & $43,7 \pm 1,11 \mathrm{Aa}$ & $44,0 \pm 1,47 \mathrm{Aa}$ \\
\hline G 3 & $36,5 \pm 2,18 \mathrm{ABa}$ & $34,7 \pm 2,66 \mathrm{Aab}$ & $35,2 \pm 3,28 \mathrm{ABab}$ & $31,7 \pm 2,06 \mathrm{Bb}$ \\
\hline G 4 & $34,2 \pm 3,07 \mathrm{Ba}$ & $33,2 \pm 2,90 \mathrm{Aa}$ & $30,5 \pm 3,59 \mathrm{Ba}$ & $30,7 \pm 3,71 \mathrm{Ba}$ \\
\hline \multicolumn{5}{|c|}{ Volume globular médio (fL) } \\
\hline G 1 & $50,1 \pm 0,43 \mathrm{Aa}$ & $48,3 \pm 1,16$ Аа & $48,0 \pm 0,72 \mathrm{Aa}$ & $47,9 \pm 0,81 \mathrm{Ba}$ \\
\hline G 2 & $52,7 \pm 1,32 \mathrm{Aa}$ & $48,2 \pm 2,54 \mathrm{Aa}$ & $49,7 \pm 3,29$ Aа & $48,4 \pm 2,67 \mathrm{Ba}$ \\
\hline G 3 & $45,2 \pm 0,52 \mathrm{Aa}$ & $47,1 \pm 3,00 \mathrm{Aa}$ & $43,2 \pm 1,17 \mathrm{Aa}$ & $42,8 \pm 3,90 \mathrm{Ba}$ \\
\hline G 4 & $47,2 \pm 2,39 \mathrm{Ab}$ & $55,0 \pm 7,47 \mathrm{Ab}$ & $55,0 \pm 8,59 \mathrm{Ab}$ & $67,2 \pm 11,6 \mathrm{Aa}$ \\
\hline \multicolumn{5}{|c|}{ Hemoglobina globular média (pg) } \\
\hline G 1 & $16,1 \pm 0,45 \mathrm{Aa}$ & $16,4 \pm 0,40 \mathrm{Aa}$ & $15,8 \pm 0,46 \mathrm{Aa}$ & $14,7 \pm 1,11 \mathrm{Ba}$ \\
\hline G 2 & $17,2 \pm 0,58 \mathrm{Aa}$ & $16,4 \pm 0,68 \mathrm{Aa}$ & $16,7 \pm 0,96 \mathrm{Aa}$ & $16,3 \pm 0,73 \mathrm{ABa}$ \\
\hline G 3 & $13,0 \pm 1,05 \mathrm{Aa}$ & $13,9 \pm 1,47 \mathrm{Aa}$ & $12,4 \pm 0,82 \mathrm{Aa}$ & $12,0 \pm 0,68 \mathrm{Ba}$ \\
\hline G 4 & $14,9 \pm 0,62 \mathrm{Ac}$ & $18,1 \pm 2,63 \mathrm{Ab}$ & $17,7 \pm 2,52 \mathrm{Abc}$ & $21,2 \pm 3,36 \mathrm{Aa}$ \\
\hline \multicolumn{5}{|c|}{ Neutrófilos segmentados $(/ \mu \mathrm{L})$} \\
\hline G 1 & $6.793 \pm 688 \mathrm{Aa}$ & $5.179 \pm 1.152 \mathrm{Aa}$ & $4.309 \pm 774 \mathrm{Aab}$ & $2.527 \pm 705 \mathrm{Ab}$ \\
\hline G 2 & $4.406 \pm 495 \mathrm{Aa}$ & $4.046 \pm 755 \mathrm{Aa}$ & $3.059 \pm 264 \mathrm{Aa}$ & $3.331 \pm 287 \mathrm{Aa}$ \\
\hline G 3 & $5.924 \pm 1.654 \mathrm{Aab}$ & $5.848 \pm 985 \mathrm{Aa}$ & $2.717 \pm 577 \mathrm{Ab}$ & $3.634 \pm 564 \mathrm{Aab}$ \\
\hline G 4 & $8.062 \pm 1.121 \mathrm{Aa}$ & $5.016 \pm 1.386 \mathrm{Aab}$ & $3.253 \pm 952 \mathrm{Ab}$ & $4.900 \pm 1.705 \mathrm{Aab}$ \\
\hline \multicolumn{5}{|c|}{ Linfócitos $(/ \mu \mathrm{L})$} \\
\hline G 1 & $3.342 \pm 461 \mathrm{Ab}$ & $5.282 \pm 964 \mathrm{Aab}$ & $5.214 \pm 840 \mathrm{Aab}$ & $6.771 \pm 783 \mathrm{Aa}$ \\
\hline G 2 & $3.839 \pm 856 \mathrm{Ab}$ & $5.783 \pm 730 \mathrm{Aab}$ & $6.511 \pm 1.037 \mathrm{Aa}$ & $6.631 \pm 861 \mathrm{Aa}$ \\
\hline G 3 & $4.744 \pm 1.430 \mathrm{Ab}$ & $5.954 \pm 1.700 \mathrm{Aab}$ & $7.206 \pm 1.678 \mathrm{Aa}$ & $6.552 \pm 460 \mathrm{Aab}$ \\
\hline G 4 & $2.662 \pm 444 \mathrm{Ab}$ & $4.624 \pm 241 \mathrm{Aa}$ & $5.671 \pm 950 \mathrm{Aa}$ & $4.244 \pm 128 \mathrm{Aa}$ \\
\hline
\end{tabular}

Letras maiúsculas diferentes indicam diferenças entre grupos, e letras minúsculas diferentes indicam diferenças entre momentos pelo teste Tukey $(\mathrm{P}<0,05)$.

Não houve diferença significativa na contagem de leucócitos entre grupos ou entre momentos, e os valores variaram de $8,47 \pm 1,27\left(\times 10^{3} / \mu \mathrm{L}\right)$ a $11,92 \pm 0,94 \quad\left(x 10^{3} / \mu \mathrm{L}\right)$. Costa et al. (1991) verificaram que fatores etários exerceram influência significativa no número total de leucócitos de bovinos da raça Nelore, com pequenas variações até aos 12 meses de idade, e que, a partir daí, ocorria decréscimo expressivo na contagem dessas células.
Sabe-se que há variação entre espécies quanto ao tipo de leucócito predominante ao nascimento. Em bovinos, verifica-se predominância de neutrófilos segmentados em relação à quantidade de linfócitos, com inversão dessa proporção com o avançar da idade (Jain, 1993; Jones e Allison, 2007). À exceção dos bezerros do grupo 2, o número de neutrófilos segmentados decresceu com o avançar da idade (Tab. 1), o que já foi também observado por Mohri et al. (2007). Não 
foi verificada influência da raça ou do número de parições quanto a esse parâmetro.

Notou-se aumento na contagem de linfócitos com o avançar da idade (Tab. 1), corroborando com o relatado por Mohri et al. (2007), e os valores verificados às $12-24$ horas de idade foram significativamente menores que aos 30 dias em todos os grupos, à exceção dos bezerros do grupo 3, nos quais a maior contagem foi verificada aos 15 dias de idade. Jones e Allison (2007) afirmaram que bezerros normalmente têm poucos linfócitos e que sua contagem aumenta com o avançar da idade até ultrapassar o número de neutrófilos segmentados dos seis aos oito meses de idade. No presente estudo, esse comportamento foi notado mais precocemente, com os bezerros atingindo relação neutrófilo:linfócito considerada normal para animais adultos por volta de 15 dias de idade.

As contagens de monócitos variaram de 73 a 300 células/ $\mu \mathrm{L}$, e as de eosinófilos de 73 a 318 células $/ \mu \mathrm{L}$. Diferentemente da tendência observada por Fagliari et al. (1998), as contagens de monócitos e eosinófilos não aumentaram com a idade. Jain (1993) relatou que, em alguns animais, o número de eosinófilos circulantes pode ser influenciado pela idade, e Costa et al. (1991) verificaram aumento da contagem de eosinófilos em animais com 24 a 48 meses de idade. A contagem de basófilos variou de 72 a 108 células $/ \mu L$. Neste estudo, os resultados não foram influenciados pela idade, assim como nos relatos de Fagliari et al. (1998). Em ruminantes normais, os basófilos estão presentes em pequeno número $\mathrm{e}$ frequentemente não são encontrados na contagem diferencial manual (Jones e Allison, 2007).

O valor médio de proteína total sérica foi significativamente menor nos bezerros do grupo 3 às 12-24 horas de vida quando comparado aos dos demais grupos (Tab. 2). Somente nos animais do grupo 2 foi constatada diferença entre momentos, com teores aos 30 dias de idade significativamente menores que os dos demais, confirmando o já relatado por Mohri et al. (2007).

Tabela 2. Médias e erros-padrão da média do teor de proteína total sérica, albumina e globulinas de bezerros Canchim-Nelore, filhos de vacas primíparas (G1) e pluríparas (G2) e de bezerros da raça Holandesa, filhos de vacas primíparas (G3) e pluríparas (G4), às 12-24h após o nascimento, e aos sete, 15 e 30 dias de idade.

\begin{tabular}{ccccc}
\hline Grupo & \multicolumn{4}{c}{ Momento } \\
\cline { 2 - 5 } & $12-24$ horas & dias & 15 dias & 30 dias \\
\hline & & Proteína total $(\mathrm{g} / \mathrm{dL})$ & \\
G 1 & $6,57 \pm 0,30 \mathrm{ABa}$ & $7,00 \pm 0,35 \mathrm{Aa}$ & $7,00 \pm 0,16 \mathrm{Aa}$ & $6,47 \pm 0,19 \mathrm{Aa}$ \\
G 2 & $8,25 \pm 0,28 \mathrm{Aa}$ & $7,40 \pm 0,22 \mathrm{Aab}$ & $6,71 \pm 0,07 \mathrm{Aab}$ & $6,09 \pm 0,07 \mathrm{Ab}$ \\
G 3 & $6,14 \pm 0,75 \mathrm{Ba}$ & $7,41 \pm 0,79 \mathrm{Aa}$ & $6,38 \pm 0,42 \mathrm{Aa}$ & $6,53 \pm 0,76 \mathrm{Aa}$ \\
G 4 & $6,38 \pm 0,33 \mathrm{ABa}$ & $6,02 \pm 0,52 \mathrm{Aa}$ & $6,36 \pm 0,15 \mathrm{Aa}$ & $5,45 \pm 0,23 \mathrm{Aa}$ \\
& & Albumina $(\mathrm{g} / \mathrm{dL})$ & \\
G 1 & $1,92 \pm 0,09 \mathrm{Aa}$ & $2,34 \pm 0,17 \mathrm{Aa}$ & $2,54 \pm 0,10 \mathrm{Aa}$ & $2,70 \pm 0,09 \mathrm{Aa}$ \\
G 2 & $1,73 \pm 0,06 \mathrm{Ab}$ & $2,20 \pm 0,06 \mathrm{Aab}$ & $2,46 \pm 0,02 \mathrm{Aab}$ & $2,71 \pm 0,03 \mathrm{Aa}$ \\
G 3 & $1,98 \pm 0,17 \mathrm{Ab}$ & $2,42 \pm 0,26 \mathrm{Aab}$ & $2,44 \pm 0,38 \mathrm{Aab}$ & $2,81 \pm 0,29 \mathrm{Aa}$ \\
G 4 & $1,90 \pm 0,26 \mathrm{Aa}$ & $2,66 \pm 0,40 \mathrm{Aa}$ & $2,13 \pm 0,39 \mathrm{Aa}$ & $2,08 \pm 0,13 \mathrm{Aa}$ \\
& & $\mathrm{Globulinas}(\mathrm{g} / \mathrm{dL})$ & & \\
G 1 & $4,65 \pm 0,37 \mathrm{Ba}$ & $4,66 \pm 0,48 \mathrm{ABa}$ & $4,46 \pm 0,20 \mathrm{Aa}$ & $3,77 \pm 0,20 \mathrm{Aa}$ \\
G 2 & $6,52 \pm 0,32 \mathrm{Aa}$ & $5,20 \pm 0,19 \mathrm{Aab}$ & $4,25 \pm 0,08 \mathrm{Abc}$ & $3,38 \pm 0,10 \mathrm{Ac}$ \\
G 3 & $4,16 \pm 0,61 \mathrm{Ba}$ & $4,99 \pm 0,63 \mathrm{ABa}$ & $3,94 \pm 0,23 \mathrm{Aa}$ & $3,72 \pm 0,55 \mathrm{Aa}$ \\
G 4 & $4,48 \pm 0,28 \mathrm{Ba}$ & $3,36 \pm 0,73 \mathrm{Ba}$ & $4,23 \pm 0,32 \mathrm{Aa}$ & $3,37 \pm 0,36 \mathrm{Aa}$ \\
\hline
\end{tabular}

Letras maiúsculas diferentes indicam diferenças entre grupos, e letras minúsculas diferentes indicam diferenças entre momentos pelo teste Tukey $(\mathrm{P}<0,05)$.

A concentração sérica de albumina aumentou a partir do nascimento nos bezerros dos grupos $2 \mathrm{e}$ 3 (Tab. 2). Resultado semelhante também foi verificado por Mohri et al. (2007).
O teor sérico de globulinas foi significativamente maior nos animais do grupo 2 que nos demais grupos às 12-24 horas e aos sete dias de idade (Tab. 2). Nesse mesmo grupo, verificou-se 
diminuição da concentração de globulinas no decorrer dos 30 dias de observação, o que não ocorreu nos demais grupos. Mohri et al. (2007) verificaram mudanças similares nos teores séricos de proteína total e de globulina.

A dinâmica das alterações hematológicas normais verificadas com o avançar da idade é complexa e pode ser diferente de acordo com a raça do bezerro e o número de parições da vaca, sendo necessário atenção na interpretação dos dados laboratoriais de animais sadios e enfermos

Palavras-chave: bezerro, neonato, hemograma, proteína sérica

\begin{abstract}
The influence of age, breed, and parity on hemogram and protein profile was evaluated in CanchimNelore and Holstein calves, born from primiparous or multiparous cows. Blood samples were taken from 12 to $24 \mathrm{~h}$ after birth and at 7, 15, and 30 days of age, in which hemogram, total protein, albumin and globulin concentrations were determined. Lymphocyte count was the only parameter influenced by age of calf. Canchim-Nelore calves born from primiparous cows presented significant alterations in hemoglobin, globular volume, and mature neutrophil count; while calves from multiparous cows showed total protein, albumin, and globulins influenced by age. In Holstein calves from primiparous cows, the age influenced globular volume, mature neutrophil count, and albumin levels; while in calves from multiparous cows the age influenced on erythrocyte count, $M C V, M C H$, and mature neutrophil count. The alterations noted in total protein and albumin and globulin levels were not uniform among groups.
\end{abstract}

Keywords: calf, newborn, hemogram, serum proteins

\section{AGRADECIMENTOS}

À Fundação de Amparo à Pesquisa do Estado de São Paulo (FAPESP), pelo auxílio financeiro concedido e pelas bolsas de pesquisa.

\section{REFERÊNCIAS BIBLIOGRÁFICAS}

BIRGEL, E.H. Hematologia clínica veterinária. In: BIRGEL, E.H.; BENESI, F.J. (Eds). Patologia clínica veterinária. São Paulo: Sociedade Paulista de Medicina Veterinária, 1982. p.2-34.

COSTA, J.N.; BENESI, F.J.; BIRGEL, E.H. et al. Fatores etários no leucograma de fêmeas zebuínas sadias da raça Nelore (Bos indicus). Cienc. Rural, v.30, p.399-403, 2000.

FAGLIARI, J.J.; SANTANA, A.E.; LUCAS, F.A. et al. Constituintes sanguíneos de bovinos recém-nascidos das raças Nelore (Bos indicus) e Holandesa (Bos taurus) e de bubalinos (Bubalus bubalis) da raça Murrah. Arq. Bras. Med. Vet. Zootec., v.50, p.253-262, 1998.
GETTY, S.M.; BECK, C.C.; BROWN, L.D. et al. Effect of iron on hematology and growth of calves. J. Anim. Sci., v.27, p.712-717, 1968.

JAIN, N.C. Essentials of Veterinary Hematology. Philadelphia: Lea \& Febiger, 1993. 417p.

JONES, M.L.; ALLISON, R.W. Evaluation of the ruminant complete blood cell count. Vet. Clin. N. Am.: Food Anim. Pract., v.23, p.377402, 2007.

MOHRI, M.; SHARIFI, K.; EIDI, S. Hematology and serum biochemistry of Holstein dairy calves: Age related changes and comparison with blood composition in adults. Res. Vet. Sci., v.83, p.30-39, 2007.

THRALL, M.A. Hematologia e bioquímica clínica veterinária. São Paulo: Roca, 2007. 582p. 